\title{
Aproximações e distanciamentos ao suicídio: analisadores de um serviço de atenção psicossocial
}

\section{Approaches and detachments towards suicide: analyzers of a psychosocial care service}

\author{
Luciana França Cescon \\ Prefeitura Municipal de Santos. Secretaria Municipal de Gestão. \\ Santos, SP, Brasil. \\ E-mail: lucianacesconळyahoo.com.br
}

\section{Angela Aparecida Capozzolo}

Universidade Federal de São Paulo. Departamento de Gestão e Cuidados em Saúde. Santos, SP, Brasil.

E-mail: capozzolo.angelaœgmail.com

\section{Laura Camara Lima}

Universidade Federal de São Paulo. Departamento de Saúde, Clínica e Instituições. Santos, SP, Brasil.

E-mail: camara.lima.laura®gmail.com

\section{Correspondência}

Luciana França Cescon

Av. Brasil, 600, sala 1.003. Praia Grande, SP, Brasil. CEP $11713-030$.

\section{Resumo}

Este artigo é produto de uma pesquisa-intervenção de perspectiva cartográfica, cujo objetivo foi investigar a atenção ao suicídio de um serviço de atenção psicossocial em um município de São Paulo. O percurso metodológico foi construído de forma dinâmica, em que as etapas finais foram projetadas em função da análise dos dados produzidos nas etapas iniciais. Os instrumentos utilizados inicialmente foram: estudo de prontuários, análise de fluxos de atendimentos, diários de campo e entrevistas semiestruturadas. As análises revelaram um processo de trabalho centrado em consultas psiquiátricas e na medicalização do sofrimento, no qual a atenção ao suicídio era pouco problematizada. Em um segundo momento, realizaram-se rodas de conversa com trabalhadores para compartilhar os dados e as análises iniciais e discutir as questões que emergiram a partir dessas informações. As intervenções mobilizaram os profissionais a repensarem o seu processo de trabalho. A equipe retomou os espaços de educação permanente, com o objetivo de analisar as ofertas de atenção psicossocial que produziam e, a partir desses encontros, repensou uma oferta de cuidado que valorizasse a escuta e o acolhimento não apenas na atenção ao suicídio, mas ao sofrimento mental. A pesquisa gerou também um blog sobre atenção ao suicídio.

Palavras-chave: Suicídio; Educação Permanente; Saúde Mental; Processo de Trabalho em Saúde. 


\section{Introdução}

This article is the product of a research-intervention of cartographic perspective, whose objective was to investigate attention to suicide in a psychosocial care service in a municipality of São Paulo. The methodological trajectory was dynamically built, in which the final stages were projected based on the analysis of data produced in the initial stages. The instruments used initially were: study of medical records, analysis of care attendance flows, field journals, and semi-structured interviews. The analyses revealed a work process centered on the offer of psychiatric consultations and the medication of suffering, in which the care to suicide was little problematized. In a second moment, conversation groups were held with the workers to share the data and the analysis produced, and to discuss issues emerging from them. The interventions encouraged professionals to rethink their work process. The team resumed the spaces of permanent education, with the objective of analyzing the psychosocial care offerings they produced. From these meetings, they rethought an offer of care that valued listening and welcoming not only in the care to suicide but also to mental suffering. The research also generated a blog about suicide awareness.

Keywords: Suicide; Permanent Education; Mental Health; Health Work Process.
O suicídio pode ser definido como "ato deliberado, intencional, de causar morte a si mesmo; iniciado e executado por uma pessoa que tem clara noção ou forte expectativa de que o desfecho seja fatal e resulte em sua própria morte" (Bertolote, 2012, p. 21). O suicídio hoje é compreendido como um fenômeno multidimensional, que resulta de uma interação complexa entre fatores ambientais, sociais, fisiológicos, genéticos e biológicos, sendo considerado um tema tabu em muitas sociedades.

As taxas de suicídio aumentaram $60 \%$, nos últimos 45 anos, e representam a $13^{\text {a }}$ causa mortis da população mundial. Em 2012, 804 mil óbitos por suicídio foram registrados no mundo. 0 fenômeno atinge todas as faixas etárias e encontra-se dentre as três principais causas de morte entre indivíduos de 15 a 44 anos, em muitos países (Botega, 2014; Conte et al., 2012). Um estudo recente, publicado pela Organização Panamericana de Saúde (OPS, 2016), atesta que a cada 40 segundos uma pessoa atenta contra a própria vida. Bahls e Botega (2007) alertam para o fato de que os números contabilizados são subestimados, uma vez que alguns suicídios são considerados e/ou registrados como acidentes, e outros como morte com causa indeterminada.

Por ser um país populoso, o Brasil fica em oitavo lugar no mundo em relação ao número de mortes autoinfligidas; isso ocorre a despeito de possuir um coeficiente de suicídio considerado relativamente baixo (menos de oito por 100 mil habitantes/ano) se comparado ao de países do hemisfério norte, que registram taxas de 20 a 30 por 100 mil habitantes/ ano (Botega, 2014). Em 2012, por exemplo, foram registradas 11.821 mortes por suicídio, no país, sendo 9.198 homens e 2.623 em mulheres (WHO, 2014). Esse número representou um aumento de 10,4\%, em relação a 2002, sendo que o aumento foi de $17,8 \%$, entre mulheres, e de 8,2\%, entre os homens (Ferreira Junior, 2015). Entre 2011 e 2016, foram registrados 62.804 óbitos, classificados nessa categoria, perfazendo uma média de 11 mil suicídios por ano (Brasil, 2017).

Devido à diversidade e à complexidade de situações que envolvem esse ato extremo, ele pode ser analisado sob várias perspectivas biológicas, genéticas, sociais, culturais e ambientais 
(Bertolote, 2012; CFP, 2013; Quental, 2009). O comportamento suicida tem sido frequentemente associado a quadros de transtornos psiquiátricos, como depressão e esquizofrenia, ou ao abuso de álcool e outras drogas (ABP, 2014). Entretanto, não cabe a generalização de que o fenômeno deva ser considerado, única e exclusivamente, decorrente de um problema de ordem psicopatológica, ou de alguma desordem social; nem que ele esteja ligado, de forma unívoca e simplista, a determinados acontecimentos da vida, como rompimentos amorosos ou perda de emprego, entre outros (Kovács, 2008). Ocorre que algumas pessoas, diante de situações desesperadas, se apegam à vida, enquanto outras cometem suicídio (Solomon, 2014).

Contrariando a concepção de suicídio como evento de foro íntimo, Marquetti (2014) apresenta o suicídio como uma forma de comunicação imagética, que envolve estetização, mensagens, cenários construídos ou utilizados e os receptores dessa forma de comunicação, os espectadores. Afirma que a intersubjetividade estabelecida entre o suicida e seu espectador (presente ou póstumo) aponta para as controvérsias da sociedade moderna e da cultura ocidental. Para a autora, o suicídio é uma forma de transgressão às regras do públicoprivado e às rígidas prescrições do lugar da morte na sociedade atual.

Pesquisas sobre prevenção apontam para o fato que o desfecho nefasto pode ser evitado, na maioria das vezes, caso haja o devido acolhimento ao sofrimento, e acompanhamento da situação (Brasil, 2013). Estima-se ainda que, para cada suicídio cometido, de cinco a dez pessoas (familiares e amigos) são fortemente afetadas social, emocional e economicamente. Trata-se de um importante problema de saúde coletiva, onde as vítimas em potencial e os chamados "sobreviventes" (pessoas impactadas por um suicídio de parente, colega ou amigo) necessitam de atenção especial (CVV, 2013; Soares et al., 2011). Para além das estatísticas, o sofrimento, que está por trás de um suicídio consumado, de uma tentativa ou de uma ideação suicida, é um fator que não pode ser ignorado pelos profissionais de saúde e pela sociedade, em geral.

Apesar de não ser uma problemática relacionada unicamente com a área da saúde, é fundamental que os profissionais que nela trabalham estejam (e se sintam) capacitados para prestar atendimentos a usuários que manifestem ideação suicida. No Brasil, o Ministério da Saúde criou, em 2006, a Estratégia Nacional para Prevenção do Suicídio, que propõe o desenvolvimento de ações de promoção de qualidade de vida, de educação, de proteção e de recuperação da saúde; a organização de linhas de cuidado integrais envolvendo todos os níveis de atenção e de educação permanente, voltados aos profissionais de saúde (Brasil, 2006a).

Entretanto, o que se observa hoje é que ainda há um longo caminho a percorrer no que se refere à atenção, prevenção e posvenção do suicídio (cuidado aos impactados após morte confirmada). Apesar de existirem algumas experiências de estruturação de redes e de programas municipais de prevenção, essas iniciativas ainda são pouco expressivas (Conte et al., 2012). Heck et al. (2012) destacam a importância de instituir espaços de escuta e acolhimento nos serviços para possibilitar um cuidado a essas situações.

O tema, no entanto, é mobilizador e provoca nos profissionais uma série de sentimentos, julgamentos morais e/ou religiosos, angústias e questionamentos relacionados ao movimento de atentar sobre a própria vida, que resultam em diferentes aproximações e modos de conduzir essas situações. As inquietações decorrentes da percepção de dificuldades encontradas pela equipe em acolher e oferecer uma atenção adequada às pessoas com ideação suicida e tentativa de suicídio que buscavam atendimento em serviço de atenção psicossocial de um município de São Paulo levaram à realização desta pesquisa-intervenção que resultou em uma dissertação de mestrado.

\section{Percurso metodológico: perspectiva, estratégias e dispositivos}

Trata-se de investigação de natureza mista, compreendendo um estudo de documentos (prontuários), a produção direta de dados com entrevistas, observação participante e proposições coletivas em contexto institucional. O objetivo foi investigar a atenção ao suicídio em um Centro de Atenção Psicossocial (Caps III) em um município de 
São Paulo. Como uma das pesquisadoras integrava a equipe do serviço, a opção metodológica foi pela pesquisa-intervenção, na perspectiva cartográfica.

A perspectiva cartográfica consiste no acompanhamento de processos, e não na representação de objetos, e pressupõe que o desenho de uma pesquisa sofra transformações ao longo de seu próprio processo e que o pesquisador modifique e seja modificado pela experiência (Barros; Kastrup, 2012). Nesse contexto epistêmico, as noções de sujeito e objeto, de pesquisador e campo de pesquisa, são colocadas em análise. Considera-se que não existe um mundo dado - conhecer é transformar e constituir a realidade (Rolnik, 2007). Segundo tal formulação, sujeito e objeto do conhecimento - pesquisador e pesquisado, - se constituem no mesmo momento, no mesmo processo (Barros; Kastrup, 2012). Nessa perspectiva não há coleta de dados, mas produção de dados por diferentes estratégias e dispositivos, como a observação participante e as entrevistas semiestruturadas, que para Deleuze são "máquinas que fazem ver e falar" (Kastrup; Barros, 2009, p. 78); sendo fundamental que o pesquisador se deixe afetar pela experiência e colocar em análise suas implicações com o objeto de pesquisa/intervenção. Enquanto na etnografia, por exemplo, o pesquisador se inclui na pesquisa, agindo com os sujeitos do campo como se fosse um deles na busca de informações, na cartografia se espera que o pesquisador mergulhe no campo, se deixando "levar por esse campo coletivo de forças" (Barros; Kastrup, 2012, p. 56-57). Esses pressupostos vêm viabilizando a construção de espaços de problematização coletiva das práticas (Rocha; Aguiar, 2003).

O percurso metodológico foi construído de forma dinâmica, retroalimentada, em que as etapas finais foram projetadas, em função da análise dos dados produzidos nas etapas iniciais. Todas as pesquisadoras contribuíram no desenho da pesquisa, na definição dos instrumentos, no levantamento e sistematização de materiais e nas análises. Os instrumentos e procedimentos previstos inicialmente foram: estudo de prontuários, análise de fluxos de atendimentos, diários de campo e entrevistas semiestruturadas. Em um segundo momento, reuniram-se os trabalhadores para rodas de conversa. As atividades de campo foram realizadas pela pesquisadora-trabalhadora, mestranda do Programa de Pós-Graduação de Ensino em Ciências da Saúde, modalidade profissional. Vale ressaltar que as duas outras pesquisadoras eram a orientadora e a coorientadora da mestranda.

Os procedimentos realizados são apresentados sinteticamente a seguir:

- Levantamento de todos os prontuários dos novos casos, que chegaram ao serviço e que foram atendidos na triagem, no período de um ano e sete meses, compreendido entre os meses: de maio de 2012 e de dezembro de 2013 (esse período foi delimitado por conveniência dos pesquisadores). Identificaram-se aqueles cujos históricos apresentavam algum registro de tentativa de suicídio ou de ideação suicida. Foi considerado o discurso expresso dos usuários em relação à ideação suicida e também frases de alerta (Werlang; Botega, 2004) que davam pistas do risco de suicídio, como: Eu não aguento mais; $\varepsilon u$ sou um perdedor e um peso pros outros; Os outros vão sermais felizes sem mim, Eu gostaria de um remédio que me fizesse dormir para sempre.

Nos prontuários selecionados foram sistematizadas as informações relativas ao percurso dos usuários no serviço, tais como: tempo de espera para o primeiro agendamento, tempo de espera para primeira consulta, profissionais envolvidos, ações de cuidado ofertadas, retorno ou encaminhamento para outro serviço.

- Realização de entrevistas semiestruturadas com profissionais de diferentes áreas. Foram entrevistadas as cinco profissionais responsáveis pelo primeiro contato com os novos usuários e decidiam o seu percurso no serviço (uma enfermeira, duas psicólogas, uma terapeuta ocupacional e uma assistente social). Também foram feitas entrevistas semiestruturadas com os três psiquiatras que atendiam na unidade. 0 roteiro de entrevistas buscou recolher concepções e experiências vividas pelos profissionais em relação ao suicídio e apreender a atenção que ofertavam. 
- Construção de um fluxograma do percurso do usuário, para visualização da organização do serviço em relação à atenção ao suicídio.

- Realização de quatro rodas de conversa com os trabalhadores, detalhadas adiante.

- Levantamento, ao longo do processo, de um conjunto de materiais diversos sobre suicídio: filmes, músicas, contos, poemas, artigos. Esses materiais foram utilizados como disparadores para as rodas de conversa e depois disponibilizados em um blog.

A experiência da pesquisadora-trabalhadora foi registrada em diário, com anotações dos acontecimentos, percepções sentimentos e pensamentos que a afetaram durante o processo. O diário de campo é um instrumento fundamental (Hess, 2006), para dar conta dessa dupla inserção de uma das pesquisadoras que também é trabalhadora do serviço, e das questões filosóficas, éticas e metodológicas decorrentes.

Durante toda a realização da investigação, as pesquisadoras se ativeram às normas e procedimentos éticos da Declaração de Helsinque e da legislação brasileira, nos termos da Resolução $n^{0}$ 466/2012 do Conselho Nacional de Saúde. 0 projeto foi registrado nas instâncias competentes e aprovado, em janeiro de 2015, pelo Comitê de Ética em Pesquisa da Universidade proponente sob parecer $n^{0}$ 933.106.

\section{Análises das implicações do pesquisador e produção de dados}

Desde o início da pesquisa haviam sido previstas duas etapas: a primeira, que buscava compreender a organização do trabalho e a problemática envolvida na atenção a pessoas com ideação ou tentativa de suicídio que chegavam ao serviço; e a segunda, de discussão coletiva com a equipe do serviço a respeito dos dados produzidos, na perspectiva de contribuir para repensar a atenção ao suicídio na rede psicossocial.

Os dados produzidos na primeira etapa foram discutidos e analisados coletivamente pelas pesquisadoras: o fluxograma, em suas entradas e entraves, relativos às demandas que chegam e às ofertas que o serviço produz; e a fala dos profissionais em relação ao trabalho no serviço e ao suicídio. Em um primeiro momento, as entrevistas foram lidas separadamente, por cada uma das pesquisadoras, buscando-se identificar temas, diferentes posicionamentos, bem como impressões e problematizações que emergiram durante a leitura. Em um segundo momento, as análises foram compartilhadas e trabalhadas conjuntamente.

Ocorreram diversos encontros entre as pesquisadoras para o exame atento das experiências produzidas pelos diferentes instrumentos e dispositivos utilizados na pesquisa: registros dos prontuários, sistematização das condutas dos profissionais que o fluxograma revela, as entrevistas e as anotações do diário. Esses encontros permitiram refinamento analítico e também análise das implicações, em especial, da pesquisadora-trabalhadora. Além de estar atuando no campo de pesquisa durante todo o percurso, partia-se ainda da hipótese de que o equipamento não estava oferecendo o cuidado adequado para a demanda do suicídio. Para Merhy (2004a, p. 23), o sujeito implicado, ao mesmo tempo pesquisador e pesquisado, mobiliza-se para produzir conhecimento a partir de certos incômodos, na busca de um saber militante: "Neste tipo de processo a implicação é estruturante do processo, coloca-se sob análise a si mesmo em ação e intenção. O processo é obrigatoriamente auto analítico". A análise se deu ao longo do trabalho, nos questionamentos em campo, tanto como pesquisadora quanto trabalhadora e nos desdobramentos do estudo.

A partir dessas análises, foi possível perceber que havia muito sofrimento entre os trabalhadores sentimento de impotência, fragilidade, sobretudo em relação ao suicídio, mas não somente isso. Havia também insatisfação e desânimo com o próprio trabalho, que paralisavam algumas ações individuais e conjuntas.

Assim, aprimoramos as estratégias pensadas para o segundo momento da pesquisa, ampliando o seu objetivo inicial, que se restringia às questões relativas ao suicídio, para a criação de espaços coletivos com a equipe, nos quais os profissionais tivessem oportunidade de falar do próprio trabalho e pudessem incluir questões de seu interesse, ou 
questões que gostariam de debater. Foi possível perceber que os movimentos da investigação (levantamento dos dados dos prontuários, entrevistas e as conversas informais) mobilizaram gradativamente os profissionais, despertando e intensificando o desejo de trocarem ideias sobre o tema do suicídio, mas também, e sobretudo, sobre o próprio sofrimento no trabalho e as dificuldades que dele decorrem.

Embora prevista na estratégia que havia sido pactuada, a primeira roda de conversa ocorreu de forma improvisada, uma vez que estava difícil reorganizar formalmente a agenda de atendimentos, para possibilitar um espaço para reunião. Por sugestão dos próprios profissionais, a pesquisadora aproveitou o tempo de uma reunião rotineira de passagem de plantão para convidar os colegas para conversar. Nesse primeiro encontro, ficou aberta a possibilidade de falarem de temas que consideravam importantes. 0 exercício foi tão produtivo que os próprios participantes fizeram questão de marcar o próximo encontro para a semana seguinte; e o mesmo fenômeno de apropriação das rodas pelos trabalhadores se repetiu novamente, nas duas semanas subsequentes.

Ao todo realizaram-se quatro rodas de conversa, com duração de uma hora cada, nas quais foram apresentados os resultados das análises iniciais: mapeamento dos casos, fluxograma, percurso do usuário na unidade e temas trazidos nas entrevistas. Além das técnicas anteriormente entrevistadas individualmente (psicólogas, assistente social, terapeuta ocupacional e enfermeira), estiveram presentes outros trabalhadores da unidade (equipe de enfermagem, pessoal administrativo, acompanhantes terapêuticos e gestor). Os psiquiatras foram os únicos convidados que não participaram desses encontros.

Cada roda contou com um registro detalhado das falas, que foram analisadas buscando-se identificar incômodos, tensões, diferentes posicionamentos bem como efeitos do próprio processo de pesquisa.

Os resultados das análises das informações dos prontuários, do fluxograma, das entrevistas e das quatro rodas de conversa, foram aglutinadas em temas e reorganizadas nos itens apresentados a seguir.
Acesso ao serviço e tempo de espera para o atendimento: analisadores do cuidado

O serviço em que a pesquisa foi realizada é um dos cinco Caps III que compõem a Rede de Atenção Psicossocial, de um município de São Paulo, que já foi referência para a Reforma Psiquiátrica Brasileira. Os Caps III atendem às demandas de Saúde Mental de adultos em regime de atendimento intensivo e ambulatorial. A rede do município conta ainda com outros serviços tais como: Centro de Atenção Psicossocial Infantil, Centro de Atenção Psicossocial Álcool e Drogas, Centro de Atenção Psicossocial Álcool e Drogas Infanto-juvenil, Serviço de Reabilitação Psicossocial, entre outros.

No momento da produção de dados, o equipamento pesquisado contava com seis profissionais de nível superior de diferentes áreas (assistência social, psicologia, enfermagem e terapia ocupacional), quatro psiquiatras, além de auxiliares e técnicos de enfermagem e pessoal administrativo para atender a demanda de uma região de cerca de 87 mil habitantes. A unidade possuía 9 mil usuários cadastrados, sendo 2 mil prontuários ativos. Esse serviço oferecia acompanhamento para usuários que necessitavam de atenção intensiva e que permaneciam na unidade, de segunda à sexta-feira, das oito às 17 horas. 0 equipamento dispunha ainda de seis leitos para internação breve. Além disso, oferecia também atendimento ambulatorial com ofertas fundamentalmente de consultas psiquiátricas.

A análise do fluxograma revelou que todos os usuários que procuravam atendimento na unidade eram recebidos no balcão, pela recepcionista, que agendava uma outra data para o primeiro atendimento com um profissional de nível superior, quando então era realizada uma avaliação da sua demanda. Esse atendimento era denominado de "triagem" e o procedimento era o mesmo, independentemente do tipo de queixa e do fato de ser demanda "espontânea" ou encaminhamento de outro serviço.

As vagas para triagem eram abertas no primeiro dia útil do mês e ficavam limitadas de duas a três por dia; quando esgotadas, o usuário era orientado 
a retornar no mês seguinte, para solicitar o agendamento. 0 serviço, portanto, não previa um espaço de pronta escuta para as demandas dos usuários que permitisse compreendê-las em sua singularidade, definir necessidades de priorização do acesso ou de ofertas de ações de cuidado.

O fluxo era o mesmo para todos. Eventualmente, se o usuário trouxesse algum encaminhamento que solicitasse agilidade no atendimento, a recepcionista acionava um dos técnicos do serviço em função de plantonista, naquele dia, para avaliar ou tomar uma decisão em relação ao usuário; mas essa opção ficava reservada somente para esses casos excepcionais. Em geral, quando o usuário explicitava alguma urgência de atendimento, era orientado pela recepcionista a procurar o pronto-socorro do município.

No dia agendado para a triagem, aqueles que comparecessem eram ouvidos pelo técnico de plantão, não sendo raros os casos em que se constatava que o atendimento adequado não era ofertado na unidade, sendo encaminhados para outros serviços, nos quais recomeçariam outro percurso em busca de tratamento.

A partir da triagem, os usuários que seriam acompanhados na unidade recebiam fundamentalmente três ofertas de cuidado, sendo a primeira largamente predominante: encaminhamento para avaliação médica, inserção em atendimentos individuais ou acompanhamento em grupo com outros profissionais da equipe. Notese que, no momento de realização da pesquisa, a oferta de grupos terapêuticos e atendimentos individuais com outros profissionais ficava restrita apenas para os usuários em atendimento intensivo.

Uma densa produção no campo da saúde enfatiza a importância de uma organização dos processos de trabalho de maneira a permitir o acolhimento e escutar as demandas dos usuários para priorizar as ofertas de atendimento (Franco; Bueno; Merhy, 1999; Merhy; Feuerwerker; Cerqueira, 2010; Teixeira; Solla, 2006). Essas questões são ainda mais importantes no campo da saúde mental. A escuta e o acolhimento são dispositivos considerados fundamentais das práticas de saúde mental, para favorecer a formação de vínculos e a efetividade da intervenção terapêutica (Lancetti; Amarante, 2009). Chama atenção a organização do processo de trabalho nessa unidade, com pouco espaço de escuta e poucas ofertas, para além das consultas psiquiátricas, para os usuários com sofrimento mental.

No que diz respeito ao suicídio, entre maio de 2012 e dezembro de 2013 , período que foi realizado o levantamento, dos 828 casos novos atendidos na triagem, 115 (13,88\% do total) apresentaram em suas falas alguma referência que poderia indicar ideação suicida, ou relataram alguma tentativa contra a própria vida.

Esses 115 usuários com potencial suicida entraram no mesmo fluxo de atendimento que os demais usuários e foram encaminhados para uma avaliação psiquiátrica; sendo que este foi o único encaminhamento obtido em $49,7 \%$ dos casos. Apenas $17,4 \%$ dos casos foram encaminhados, concomitantemente, para atendimento com outro profissional ou para inserção em alguma atividade no serviço (grupos). Os demais foram encaminhados para atendimento psicológico em outros serviços, dentro ou fora da rede pública (serviços-escolas de psicologia ou outros).

No total de atendimentos, 47 pessoas informaram que já haviam tentado suicídio anteriormente. No entanto, na maioria dos casos, essa informação não se traduziu em uma atenção diferenciada, conforme Tabela 1.

\begin{tabular}{|c|c|c|c|}
\hline \multirow{2}{*}{$\begin{array}{l}\text { Tempo acumulado } \\
\text { No mesmo dia }\end{array}$} & \multicolumn{2}{|c|}{ Casos } & \multirow{2}{*}{$\begin{array}{l}\% \\
4,2\end{array}$} \\
\hline & 2 & 4,2 & \\
\hline Entre I a 7 dias & 4 & 8,5 & 12,7 \\
\hline Entre 8 a 15 dias & " & 23,5 & 36,2 \\
\hline Entre 16 a 30 dias & 10 & 21,2 & 57,4 \\
\hline Entre 31 a 60 dias & 8 & 17,1 & 74,5 \\
\hline Mais de 6I dias & ॥ & 23,3 & 97,8 \\
\hline Não informado & OI & 2,2 & 100 \\
\hline
\end{tabular}


Vale ressaltar que apenas $36,2 \%$ dos usuários foram atendidos pelo psiquiatra em um prazo inferior a 15 dias, e que $23,3 \%$ foram atendidos mais de dois meses depois da primeira vez que visitaram o equipamento.

Também para os que informam tentativa de suicídio anterior (recente ou não), a principal oferta foi a consulta com o psiquiatra. Em geral, de acordo com os dados dos prontuários, a conduta desse profissional foi medicamentosa, com agendamento de retornos médicos mensais, ou em períodos maiores, para novas avaliações.

Havia, porém, alguns casos com encaminhamento também para atendimento com psicólogo ou outro técnico da equipe (assistente social, enfermeira ou terapeuta ocupacional). Entretanto, os prontuários não trazem dados suficientes para que os pesquisadores levantem hipóteses sobre os determinantes das decisões tomadas e das condutas adotadas pelos profissionais em cada caso.

Pôde-se também constatar que não havia monitoramento das faltas ou dos abandonos dos pacientes com ideação ou tentativa de suicídio; alguns nunca voltaram depois da primeira visita, e o fato de não terem comparecido à triagem também não gerava nenhuma busca ativa por parte dos profissionais do serviço.

O mapeamento dos casos de suicídio e dos encaminhamentos que eles tiveram dentro e fora do equipamento deu visibilidade ao pouco espaço de escuta e de acolhimento previsto na organização do processo de trabalho, bem como à centralidade do modelo biomédico com poucas ofertas de outras formas de atenção, não apenas para as situações de ideação ou tentativas de suicídio, mas também para todas as demandas de sofrimento mental que chegavam ao serviço.

Pesquisas sobre prevenção ao suicídio, como dissemos anteriormente, apontam que na maioria das vezes ele pode ser evitado, caso o acolhimento e o acompanhamento funcionem. Percebe-se que o serviço pesquisado não estava conseguindo disponibilizar rapidamente uma resposta adequada às demandas de suicídio, ofertando escuta, acolhimento (imediato) e o devido acompanhamento longitudinal da situação (Brasil, 2006b, 2013; Heck et al., 2012).

\section{Aproximações e distanciamentos ao suicídio: fragilidades e potencialidades dos profissionais}

$\mathrm{Na}$ investigação com os profissionais ficou evidente que havia diferentes aproximações ao tema. Os profissionais que realizavam a triagem relacionavam o suicídio a questões psicossociais, tais como: muito sofrimento, falta de sentido na vida, solidão, impotência [...] no maior grau, impulso do desespero, uma fuga.

Porém, a associação do comportamento suicida com uma doença surgiu de forma bastante significativa: Acho que é uma doença psíquica, né? [...] Aliás, a desesperança, acho que, em si, já tem alguma coisa de doença associada, né? Porque a pessoa não ver uma luz no fim do túnel, acho que já é uma coisa doentia, né? (Técnico 1).

Para os médicos, o comportamento suicida estaria sempre relacionado a algum transtorno psiquiátrico que deveria ser diagnosticado, para que a conduta pudesse ser definida. Dentre os diagnósticos possíveis, eles destacaram três: depressivos, esquizofrênicos, ou histéricos.

Embora parte significativa dos estudos (ABP, 2014; Brasil, 2006b) apontem relações entre o suicídio e determinadas classificações psiquiátricas (depressão, transtorno bipolar e borderline aparecem frequentemente como casos com maior probabilidade de suicídio), outros autores como Hillman (2011), Berenchtein Netto (2013) e Solomon (2014) destacam como central os sofrimentos existenciais e a complexidade das questões socioeconômicas e culturais envolvidas, sendo de fundamental importância a escuta, em todas essas situações.

Apesar dos profissionais de nível superior considerarem importante oferecer um espaço de escuta e um acompanhamento com variadas formas de atenção e suporte para usuários que mencionaram ideações ou tentativas de suicídio, eles acabavam privilegiando, quase exclusivamente, o encaminhamento para atendimento com os médicos psiquiatras. Poucos marcavam um retorno na própria agenda, ou com outros técnicos. A maioria relatou que não fazia outras ofertas de apoio ou de monitoramento para os usuários que 
faltavam ou que não compareciam às triagens ou às consultas agendadas.

Ao serem indagados sobre essas questões e contradições, afirmaram que a organização do trabalho no serviço impunha um grande obstáculo para uma escuta e um cuidado diferenciado: as pessoas têm muita boa vontade, mas não têm pernas pra fazer algumas coisas (Técnico 1). Esses profissionais eram demandados a orientar usuários que haviam passado em consulta médica, os que estavam em atendimento intensivo e seus familiares, entre outros. Assim, consideravam que a quantidade de pessoas para atender dificultava acolher e escutar cada um de forma singular: é tão corrida essa triagem, por ter um balcão com mais de 30 ou 4 o pessoas lá te esperando (Técnico 3).

O território de responsabilidade da unidade foi considerado muito grande para o quadro de pessoal reduzido, uma vez que os quadros de saúde mental, ainda que leves e moderados, eram todos direcionados para os Caps III, como destaca este médico: muita gente e poucos profissionais para atender essa muita gente [...]. Nós temos aqui, no momento, três psicólogos, não é? [...] para uma população que [...] tem quinhentos mil habitantes! [...] É muito pouco (Médico 1).

Essas são questões importantes, porém, para além da sobrecarga de tarefas e da alta demanda de atendimentos, foi possível perceber a força da concepção biomédica e do ato médico para justificar que todos os usuários passassem primeiro por uma avaliação médica para diagnóstico e prescrição de medicação, refletindo também uma relação hierárquica do poder e saber médico, presente não apenas na saúde mental, mas na saúde, de forma geral. Merhy e Feuerwerker (2009, p. 35) observam que "a busca objetiva do problema biológico tem levado a que a ação do profissional esteja centrada nos procedimentos, esvaziada de interesse no outro, com escuta empobrecida".

Inicialmente parecia haver certa indiferença, certo distanciamento dos profissionais ao tema, porém, no decorrer da investigação, foi possível perceber que os profissionais sentiam dificuldade de oferecer uma escuta qualificada para essas situações:

$\varepsilon$ quantas pessoas a gente não atendeu no ambulatório, que vem com a queixa do suicídio, do desejo da morte, e a gente não dá o que a gente tem de mais rico, que é a escuta pra essas pessoas? A gente soca eles na agenda do médico, que toca remédio e [...] isso frustra a gente. (Técnico 2)

parece, ainda, a gente tem esse olhar muito biomédico, né [...]. Eu fico um pouco pensando sobre isso e sempre fico na coisa da impotência [...] de que não estou conseguindo dar conta das coisas que aparecem e acho que o suicídio esfrega isso mais ainda. aqui. (Técnico 3)

As expressões e metáforas como: o suicídio esfrega a impotência na cara, a gente soca eles na agenda do médico, que toca remédio, parecem revelar incômodos, ressentimentos ou mesmo certa violência contida; sentimento de impotência, frustração por não conseguirem realizar o trabalho da maneira idealizada.

Há muito tempo o suicídio não era discutido na equipe e somente aqueles que tinham alguma vivência anterior (pessoal ou profissional) demonstraram maior desenvoltura e facilidade para se pronunciarem sobre o tema.

Eu tive uma experiência [...]. Não era uma pessoa psicótica [...] e foi um desespero, de não ter mais emprego, de não ter mais como levar comida para casa, [...] tentou suicídio esfaqueando o abdômen, e foi pra UTI. $\varepsilon$ assim que recobrou a consciência, com as próprias mãos, arrebentou os pontos [...] pra "retentar" o suicídio. [...], não era uma questão psiquiátrica em si, né. (Técnica 2)

Havia poucos espaços de discussão coletiva para que os trabalhadores pudessem falar e pensar sobre o próprio trabalho. Ao que parece, a organização do processo de trabalho pressionava para que os trabalhadores acionassem mais dispositivos de distanciamento: você começa a não se importar com coisas que te incomodam [...] você deixa de lado as coisas que você sente [...], pra já passar por aquilo e pronto (Técnico 1).

Além disso, outro aspecto a ser considerado é que o contato com a pessoa que tentou o suicídio, ou expressa seu desejo de morte, pode causar certo sofrimento aos trabalhadores também por colocá-los 
diante da ideia da morte e da finitude, e também diante da sua própria impotência em oferecer soluções para essas situações. De certa forma, isso também poderia contribuir para as limitadas ofertas de cuidado, além da consulta e prescrição médica. Retomando os conceitos de Freud de pulsão de vida e de pulsão de morte, onde esta última é entendida como tendência ao inerte, Onocko Campos e Campos (2009) referem que um dos recalques frequentemente ativados por todos os seres humanos é o da morte. Afirmam que gostaríamos de viver o tempo todo a ignorá-la. Entretanto, os trabalhadores da saúde, que estão expostos ao contato permanente com a dor, o risco e o sofrimento, não podem evitar o contato com a morte. Por isso, esses autores consideram importante a criação de espaços nos quais essas questões possam ser analisadas, e não recalcadas e não se transformem em atuações perversas ou burocráticas da relação entre profissionais, com os usuários e as comunidades.

Percebe-se aqui que, diante do desafio que representa a atenção ao suicídio, os profissionais se veem confrontados às suas próprias dificuldades pessoais, fragilidades, em relação à morte violenta, autoinfligida, à ameaça fantasmagórica da própria morte e em relação à responsabilidade que é depositada neles pelos usuários que chegam numerosos, apresentando problemas complexos. As demandas afluem de toda parte e as tarefas são múltiplas e variadas de maneira que os profissionais não conseguem produzir respostas adequadas para todas elas.

Além disso, casos que deveriam ser acompanhados pela atenção básica acabam chegando aos Caps sob forma de demandas espontâneas, mas, sem estrutura para assimilar essa demanda, a equipe acaba, muitas vezes, encaminhando par outros serviços, inclusive ligados a instituições acadêmicas ou comunidades religiosas.

Tem sido um grande desafio a constituição das redes de atenção psicossocial (Bezerra et al., 2014; Lancetti; Amarante, 2009). Apesar de algumas iniciativas da gestão municipal para descentralizar o atendimento desses casos para serviços de atenção básica e construção de redes, no momento da pesquisa, esses processos estavam ainda incipientes. As equipes dos Caps tinham pouca interlocução com as equipes da atenção básica ou outros equipamentos da rede municipal de saúde e também com outras secretarias, o que ampliava ainda mais a sobrecarga dos profissionais.

Os movimentos da pesquisa foram mobilizando nos profissionais a necessidade de conversar sobre o suicídio e o próprio trabalho. Assim, a primeira roda de conversa foi viabilizada com a cumplicidade e parceria dos profissionais do serviço. As rodas se colocaram como um espaço importante para trabalhar as questões relativas às sensibilidades, às fragilidades, mas também às potencialidades dos trabalhadores como iremos apresentar a seguir.

\section{As rodas de conversa: os processos de trabalho e as implicações dos trabalhadores em análise}

\author{
Para Merhy (2004b, p. 8):
}

as experiências do acolhimento, mostram que se exige que os trabalhadores se vejam, explicitamente, como protagonistas da produção do seu cotidiano. Que tomem isso como uma força, que desejem isso, que queiram com isso se apossar deste fazer e torná-lo um caminho cúmplice com o mundo dos usuários, e assim transmitam alegria a partir deste tipo de processo.

Acreditando nessa ideia, a proposta de formar grupos e rodas de conversa com os trabalhadores da unidade pesquisada surgiu como possibilidade de contribuir para pactuações de novas formas de acolhimento e atendimento a esses casos.

A primeira roda foi muito marcante, pois foi uma abertura importante para repensar o trabalho e as práticas coletivas. Nesse encontro esteve em discussão o acolhimento dos usuários. Os profissionais que aceitaram participar estabeleceram um clima de confiança, em que a palavra ganhou fluidez, as guardas baixaram um pouco, as defesas coletivas relaxaram e foi possível elaborar algumas questões relativas aos dados apresentados pela pesquisadora e ao que foi mobilizado durante o processo da pesquisa. 
Foram explicitados incômodos pelo fato de os usuários não serem acolhidos por um profissional de nível superior no primeiro momento em que chegam ao serviço, para que possam receber uma escuta qualificada e ter sua demanda avaliada e encaminhada. Os técnicos presentes também manifestaram incômodo pelo fato de que a principal oferta do serviço é o agendamento com o psiquiatra, e por essa fórmula ser reproduzida inclusive pelos próprios técnicos (ou seja, por eles mesmos), sem a oferta de nenhum outro tipo de cuidado.

Destacaram um sentimento de frustração ao perceberem que foram se distanciando da possibilidade de acolher "o outro", em suas angústias e fragilidades; seja esse outro concretizado na figura dos usuários ou dos colegas de trabalho, diante dos quais se mostraram severos, intolerantes, impacientes. Ao conseguir identificar determinados aspectos em seu agir cotidiano, puderam problematizar o quanto estavam tocando, automaticamente e, talvez, alienadamente, os atendimentos, sem repensar e propor mudanças.

Esse encontro foi importante para resgatar a força da equipe e perceber que poderiam tentar modificar a organização do serviço que, afinal, era reproduzida por cada um. Perceberam ser necessário e possível resgatar certa sensibilidade e disponibilidade para o encontro com o outro, e que desse encontro podiam retirar força, coragem e apoio para modificar hábitos arraigados, e propor mudanças que trouxessem melhorias para a qualidade do trabalho com os usuários e mais bem-estar para os trabalhadores: Acho que essa ideia da gente se encontrar mais, de poder falar mais, [...] essa disponibilidade de escutar o outro, de poder falar, eu acho essencial... nós podemos abrir um espaço para falar disto (Técnica 1).

Este primeiro encontro mostrou que "no trabalho em saúde, não precisamos nos condenar ao peso da dor, do sofrimento e das carências. Também não podemos limitar nosso olhar e nossa escuta apenas ao que detectam nossos instrumentos de diagnóstico [...]. Precisamos inventar, cada um à sua maneira, formas para não nos deixarmos petrificar e não desaprendermos a ver e ouvir afetos e vivências [...] ressignificando o próprio trabalho e recriando a vida. (Brasil, 2005, p. 83)
Outra roda foi agendada para a semana seguinte, com a proposta de discutir, mais especificamente, sobre o suicídio. Inicialmente, foram apresentados os dados do levantamento realizado e a equipe mostrouse surpresa diante dos números apresentados: não imaginava que essa demanda (referindo-se ao suicídio) fosse tão significativa (Técnica 4).

A pesquisadora apresentou também uma situação, previamente selecionada, para ser discutida. Tratava-se do caso de um usuário, de 33 anos, que havia procurado o serviço, depois de 30 dias de internação em um hospital, em decorrência de uma ingestão de medicamentos seguida de tentativa de enforcamento. Na triagem, queixou-se de inquietação, insônia e crises de pânico. A conduta adotada pelo profissional técnico que o atendeu foi de agendar uma consulta psiquiátrica, que ficou marcada para 116 dias depois. Esse usuário também foi encaminhado para psicoterapia fora do serviço, e não retornou na data agendada. 0 caso suscitou muita discussão e permitiu perceber claramente o distanciamento entre: a premência da demanda/necessidade de cuidado da pessoa que buscou o serviço e a morosidade/ insuficiência da oferta de atendimento médico. Em um momento da discussão, os profissionais admitem e consideram as próprias limitações: e a gente acaba fazendo até coisa que não concorda, que naquele momento parece ser a saída mais fácil (Técnica 3).

A partir daí iniciam a discussão sobre outras possibilidades de reorganizar o processo de trabalho e o atendimento, como explicita a fala abaixo:

Como, por exemplo, esse espaço [de discussão] aqui... né, saiu dessas queixas, né, se a gente vai ficar atéo fim da vida e não vai mudar esse sofrimento, ou nós vamos fazer mudar, né? Então, nós vamos buscar esse espaço, de ter uma troca mais saudável, ou vamos ficar só contando os incêndios que apagamos, né? É... ter um espaço de reflexão, da onde a gente consiga criar outras coisas. (Técnica 2)

As próximas rodas de conversa (sempre sem a participação dos psiquiatras) seguiram o mesmo modelo da primeira, com abertura para a discussão de temas que a equipe considerava pertinente para refletir sobre sua prática. O conceito de Educação Permanente em Saúde traz como norte 
o processo educativo que coloca o cotidiano do trabalho - ou da formação - em saúde em análise, possibilitando construir espaços coletivos para a reflexão e avaliação de sentido dos atos produzidos no cotidiano. A vivência e/ou a reflexão sobre as práticas vividas é que podem produzir o contato com o desconforto e, depois, a disposição para produzir alternativas de práticas e conceitos, para enfrentar o desafio de produzir transformações (Ceccim, 2005).

Vale destacar que nos encontros também foram utilizados materiais como músicas, textos diversos e trechos de entrevistas para disparar discussões e estimular reflexões, que contribuíram para "olhar" para o suicídio e para o próprio trabalho e mobilizaram a explicitação angústias e sofrimentos, não apenas para lidar com essa demanda específica, mas com o sofrimento mental.

Essas rodas permitiram que os trabalhadores colocassem em análise a motivação, a compreensão e implicação com o próprio trabalho. O compartilhamento de fragilidades, medos, dificuldades, mas também de experiências, de conhecimentos e soluções criativas, fizeram com que as rodas de conversa mobilizassem potencialidades e impulsionassem movimentos de mudanças nas práticas, como veremos a seguir.

\section{Repensando o trabalho: repactuando o momento de educação permanente}

A partir das rodas de conversa abriram-se possibilidades de pensar, conjuntamente, estratégias que pudessem modificar o processo de trabalho, evitando a reprodução automatizada do fluxo de atendimento, e também dar mais atenção às situações que chegavam, em especial às relacionadas ao suicídio. Assim, foi proposto repensar o primeiro acolhimento e oferecer um espaço de escuta que pudesse compreender, mais amplamente, as questões que os usuários traziam, além da queixa expressa. Uma escuta, que não objetivasse apenas coletar informações cadastrais, mas que pudesse ser uma forma de cuidado qualificado.

Foi possível perceber que os profissionais assimilaram parte dos conhecimentos compartilhados nas rodas e das referências teóricas trazidas pela pesquisadora-trabalhadora, e se aproximaram, nas suas proposições, do que é preconizado para o atendimento ao suicídio (Brasil, 20o6b; Heck et al., 2012). A partir de deliberações coletivas, fizeram propostas de reorganização do trabalho e resolveram assumir um protagonismo maior nas ações de cuidado, como explicita a fala a seguir:

Isso foi o que mudou [depois de algumas conversas sobre atenção ao suicídio no cotidiano do trabalho]. Pelo menos, da minha parte, que eu atendi lá uma ideação suicida, e o médico, e o médico? Não, pera aí. Eu fico um tempo mais na triagem, tentando escutar o caso, não é só o médico que vai resolver, né? Mesmo porque o remédio não resolve hoje, né? (Técnica 3)

Considerando que a tentativa de suicídio é um dos principais fatores de risco de suicídio consumado e que deve ser acompanhada de forma terapêutica e preventiva, a equipe dispôs-se a agendar um retorno próximo e ter contato com uma pessoa de referência (familiar, cônjuge, amigo), que pudesse acompanhar o usuário mais de perto, em parceria com o serviço, nos casos em que se avaliasse que havia risco de suicídio. Também pactuou formas de registro dos atendimentos, de maneira a resguardar a possibilidade de fazer uma busca ativa aos usuários que se afastam do serviço ou do tratamento e para que pudessem monitorar as demandas e ofertas de atendimento.

0 processo da pesquisa permitiu compreender que seria impossível, para os trabalhadores, produzir cuidado às pessoas com risco de suicídio, sem questionar, de preferência coletivamente, os próprios medos, preconceitos e tabus a esse respeito. Nesse sentido, poder compartilhar as fragilidades, e não as certezas, nesses espaços de encontro que foram as rodas de conversa, foi fundamental. Ao se sentirem escutados, apoiados e participantes nas decisões coletivas, os profissionais puderam assumir posições mais ousadas, que antes lhes causavam angústia e ativavam processos defensivos. Retomouse a necessidade dos momentos de discussão dos casos, sobretudo os mais difíceis, que demandam maior atenção da equipe. Nos encontros também foi constatada a vontade que alguns profissionais sentem de estudar e se qualificar melhor.

Mobilizados pelas trocas e decisões coletivas que ocorreram durante as rodas de conversa, os 
participantes decidiram, de algum modo, perpetuálas. Comprometeram-se a retomar e manter um encontro semanal de uma hora para Educação Permanente (EP) de discussão coletiva, entre profissionais do equipamento, independentemente de ser essa uma proposta institucional. Foi ressaltada a importância desses encontros de EP, tanto para gradualmente construir novas ofertas de intervenções possíveis para os sofrimentos que chegam ao serviço, quanto para poderem qualificar o próprio trabalho.

Uma coisa tambémé abrir espaço pra gente discutir essas coisas, né, vamos discutir suicídio, vamos discutir esse delírio [...]. Vamos abrir dois dias pra gente estudar, né [...], vamos nos autosupervisionar [...]. Cada um [...] prepara alguma coisa que tem na sua formação específica e traz para discutir, ou se não deu tempo de preparar, traz um texto pra gente ler junto. (Técnica 4 ).

O trabalho de atenção em saúde mental, assim como todo o trabalho em saúde, não pode ser totalmente normatizado, e por isso são fundamentais os espaços no cotidiano do trabalho de educação permanente, em que os profissionais possam compartilhar dúvidas, incertezas, saberes e aprender coletivamente. Uma das finalidades da Educação Permanente em Saúde é contribuir para que cada coletivo possa analisar o próprio trabalho e ampliar sua capacidade de responder às necessidades dos usuários por meio de um processo de reinvenção das instituições de saúde e do seu mundo do trabalho em especial (Merhy; Feuerwerker; Ceccim, 2006).

Ao fim da pesquisa, esses encontros continuaram ocorrendo, sendo reconhecidos pelos trabalhadores como um espaço de recuperação de potência, onde eles se sentem capazes e se capacitam a estudar, discutir casos, fazer supervisões coletivas. Apesar de não ser possível afirmar com propriedade até quando duraram essas iniciativas - uma vez que a pesquisadora que lá esteve deixou o serviço algum tempo depois de ter concluído a investigação -, o que se pode afirmar, com certeza, é que durante algum tempo os profissionais retomaram coletivamente a autonomia e a capacidade de resistência.

Ao término do processo da pesquisa a dissertação foi enviada para a Coordenação da Secretaria e aos demais serviços de saúde mental do município. Os materiais do blog ${ }^{1}$, produtos do mestrado profissional que ajudaram a trabalhar com os receios e medos dos profissionais, foram disponibilizados à equipe e também a outros interessados.

Em setembro de 2016, a pesquisadora que atuava no serviço foi convidada pela coordenadora da Saúde Mental do município para um encontro sobre prevenção do suicídio (campanha Setembro Amarelo) e pôde compartilhar os resultados da pesquisa-intervenção com a rede de saúde mental, completando o que havia sido proposto inicialmente, quando do início das pactuações com a coordenação da saúde mental do município para a realização do projeto.

\section{Considerações finais}

Ao longo do percurso da pesquisa, ficou claro para pesquisadores e trabalhadores que não era possível qualificar a atenção ao suicídio, sem incluir na discussão a organização do trabalho e as dificuldades que os profissionais têm de lidar com esse tema. Questões complexas como a atenção ao suicídio precisam de mais do que protocolos e informações: o conhecimento deve ser construído coletivamente, com espaços de conversa e de reflexão e com o reconhecimento das diversas concepções, crenças, potencialidades e desafios que estão presentes neste encontro entre trabalhadores de saúde e usuários.

A retomada do espaço de educação permanente no serviço foi um importante desdobramento da pesquisa; os próprios trabalhadores se sentiram interessados e autorizados a conversar com colegas sobre os próprios preconceitos, angústias e desafios, mas também sobre suas capacidades e potencialidades individuais e coletivas. Também foi um espaço importante para construir possibilidades de lidar com situações complexas, que demandam recursos como: referenciais teóricos, tecnologias

1 Disponível em: <http://bit.ly/2EHOTsG>. 
leves, "ferramentas" e possibilidades de trabalho em equipe. Esse espaço de Educação Permanente, de análise e aprendizagem com as experiências, os encontros e desencontros vivenciados no cotidiano do trabalho, ficou vivo por algum tempo no serviço e foi importante para qualificar a atenção ao suicídio e ao sofrimento mental.

Foi possível perceber que, em um primeiro momento, a pesquisadora-trabalhadora se sentiu imbuída da missão de sensibilizar para a causa da atenção ao suicídio, o que a levou a se distanciar dos colegas mais reticentes e a proferir avaliações críticas a respeito da conduta dos profissionais do serviço, que pouco consideravam as dificuldades reais pelas quais estavam passando. Em um segundo momento, as pesquisadoras puderam, a partir da análise das implicações e do trabalho conceitual e reflexivo, ampliar o olhar. A organização do processo de trabalho, as condições em que é realizado, as limitações da própria rede de atenção psicossocial e de que modo essas dificuldades impactavam a subjetividade dos trabalhadores e afetam a qualidade do cuidado oferecido aos usuários que chegam com ideação suicida, ou tendo realizado alguma tentativa, puderam ser incluídas nas análises.

Esta experiência permitiu colocar o tema do suicídio em evidência e mostrou a importância de construir espaços coletivos de discussão entre os trabalhadores. Esses espaços de troca e deliberação são essenciais para o cuidado em saúde mental (tanto dos usuários quanto dos próprios trabalhadores), para consolidação das equipes e articulação das ações ofertadas de maneira mais consciente e propositiva e, por conseguinte, menos alienada. Os espaços de troca também fortalecem os laços entre pares, assegurando que os profissionais mantenham uma rede de cuidados entre eles, que facilita no enfrentamento dos medos e frustrações, individuais e coletivas.

Idealmente, espaços como esses deveriam ser ampliados para todos os equipamentos de atenção psicossocial e mesmo para toda rede de atenção à saúde; espaços de troca e de deliberação coletiva são essenciais para contrapor o extravasamento da violência sob todas as suas formas, que vem imperando em muitos ambientes e transformando o sofrimento mental agudo em crônico. Investir na construção desses espaços coletivos de troca e deliberação parece ser uma estratégia potente para conjurar a violência e para a construção de um projeto de atenção em saúde mental que contribua para um processo de cuidado mais efetivo.

Como novas possibilidades de estudo necessárias ao campo, sugere-se pesquisas em Caps III de diferentes regiões do Brasil, bem como estudos que abordem também a compreensão dos usuários acerca do cuidado ofertado nos casos de comportamento suicida.

\section{Referências}

\section{ABP - ASSOCIAÇÃO BRASILEIRA DE}

PSIQUIATRIA. Suicídio: informando para prevenir. Brasília, DF: CFM: ABP, 2014. Disponível em: <http://bit.ly/1DFRfAz>. Acesso em: 24 maio 2017.

BAHLS, S. C.; BOTEGA, N. J. Epidemiologia das tentativas de suicídio e dos suicídios. In: MELLO, M. F.; MELLO, A. A. F.; KOHN, R. (Org.). Epidemiologia da saúde mental no Brasil. Porto Alegre: Artmed, 2007. p. 151-172.

BARROS, L. P.; KASTRUP, V. Cartografar é acompanhar processos. In: PASSOS, E.; KASTRUP, V.; ESCÓSSIA, L. (Org.). Pistas do método da cartografia: pesquisa-intervenção e produção de subjetividade. Porto Alegre: Sulina, 2012. p. 52-75.

BERENCHTEIN NETTO, N. Suicídio: uma questão de saúde pública e um desafio para a psicologia clínica. In: CFP - CONSELHO FEDERAL DE PSICOLOGIA. $O$ suicídio e os desafios para a psicologia. Brasília, DF, 2013. p. 13-24.

BERTOLOTE, J. M. O suicídio e sua prevenção. São Paulo: Unesp, 2012.

BEZERRA, I. C. et al. "Fui lá no posto e o doutor me mandou foi pra cá”: processo de medicamentalização e (des)caminhos para o cuidado em Saúde Mental na Atenção Primária. Interface: Comunicação, Saúde, Educação, Botucatu, v. 18, n. 48, p. 61-74, 2014. Disponível em: <http://bit.ly/2EJBtbO>. Acesso em: $1^{0}$ nov. 2017.

BOTEGA, N. J. Comportamento suicida: epidemiologia. Psicologia USP, São Paulo, v. 25, n. 3, p. 231-236, 2014. Disponível em: <http://bit. ly/2EOesEB>. Acesso em: 24 maio 2017. 
BRASIL. Ministério da Saúde. Curso de formação de facilitadores de Educação Permanente em Saúde: unidade de aprendizagem: trabalho e relações na produção do cuidado em saúde. Rio de Janeiro: Fiocruz, 2005. Disponível em: <http://bit. ly/2oiZrEw>. Acesso em: 21 fev. 2017.

BRASIL. Ministério da Saúde. Portaria nº 1.876, de 14 de agosto de 2006. Institui Diretrizes Nacionais para Prevenção do Suicídio, a ser implantadas em todas as unidades federadas, respeitadas as competências das três esferas de gestão. Diário Oficial da União, Brasília, DF, 15 ago. 2006a. Seção 1, p. 65. Disponível em: <http:// bit.ly/2HD1pYk>. Acesso em: 17 abr. 2017.

BRASIL. Ministério da Saúde. Prevenção do suicídio: manual dirigido a profissionais das equipes de saúde mental. Campinas: Universidade Estadual de Campinas, 2006b. Disponível em: <http://bit.ly/2CdMioD >. Acesso em: 12 maio 2017.

BRASIL. Ministério da Saúde. Saúde Mental. Brasília, DF, 2013. (Cadernos de atenção básica, n. 34). Disponível em: 〈http://bit.ly/2lyQqVc〉. Acesso em: 12 abr. 2017.

BRASIL. Ministério da Saúde. Ministério da Saúde lança agenda estratégica de prevenção do suicídio. Brasília, DF, 2017. Disponível em: <https://goo. gl/7fnnVo>. Acesso em: 31 out. 2017.

CECCIM, R. B. Educação permanente em saúde: desafio ambicioso e necessário. Interface: Comunicação, Saúde, Educação, Botucatu, v. 9, n. 16, p. 161-177, 2005.

CFP - CONSELHO FEDERAL DE PSICOLOGIA. O suicídio e os desafios para a psicologia. Brasília, DF, 2013.

CONTE, M. et al. Programa de Prevenção ao Suicídio: estudo de caso em um município do sul do Brasil. Ciência \& Saúde Coletiva, Rio de Janeiro, v. 17, n. 8, p. 2017-2026, 2012.

CVV - CENTRO DE VALORIZAÇÃO DA VIDA. Falando abertamente sobre suicídio. São Paulo, 2013. Disponível em: <http://bit.ly/2xz3mmK > Acesso em: 13 maio 2017.
FERREIRA JUNIOR, A. O comportamento suicida no Brasil e no mundo. Revista Brasileira de Psicologia, Salvador, v. 2, n. 1, p. 15-28, 2015. Disponível em: <https://goo.gl/4eCb2G >. Acesso em: 10 maio 2017.

FRANCO, T. B.; BUENO, W. S.; MERHY, E. E. $O$ acolhimento e os processos de trabalho em saúde: o caso de Betim, Minas Gerais, Brasil. Cadernos de Saúde Pública, v. 15, n. 2, p. 345-353, 1999.

HECK, R. M. et al. Ação dos profissionais de um centro de atenção psicossocial diante de usuários com tentativa e risco de suicídio. Texto \& Contexto Enfermagem, Florianópolis, v. 21, n. 1, p. 26-33, 2012.

HESS, R. Momento do diário e diário dos momentos. In: SOUZA, E. C.; ABRAHÃO, M. H. M. B. (Org.). Tempos, narrativas e ficções: a invenção de si. Porto Alegre: EDIPUCRS, 2006. p. 89-103.

HILLMAN, J. Suicídio e alma. 4. ed. Petrópolis: Vozes, 2011.

KASTRUP, V.; BARROS, R. B. Movimentos-funções do dispositivo na prática da cartografia. In: PASSOS, E.; KASTRUP, V.; ESCÓSSIA, L. (Org.). Pistas do método da cartografia: pesquisaintervenção e produção de subjetividade. Porto Alegre: Sulina, 2009. p. 76-91.

KOVÁCS, M. J. (Org.). Morte e desenvolvimento humano. 5. ed. São Paulo: Casa do Psicólogo, 2008.

LANCETTI, A.; AMARANTE, P. Saúde mental e saúde coletiva. In: CAMPOS, G. W. S. et al. (Org.). Tratado de saúde coletiva. 2. ed. São Paulo: Hucitec; Rio de Janeiro: Fiocruz, 2009. p. 615-634. MARQUETTI, F. C. O suicídio e sua essência transgressora. Psicologia USP, São Paulo, v. 25, n. 3, p. 237-245, 2014. Disponível em: <http://bit. ly/2CcNBED>. Acesso em: 9 abr. 2017.

MERHY, E. E. O conhecer militante do sujeito implicado: o desafio de reconhecê-lo como saber válido. In: Franco TÚLIO, B.; PERES, M. A. A. (Org.). Acolher Chapecó: uma experiência de mudança do modelo assistencial, com base no 
processo de trabalho. São Paulo: Hucitec, 2004a. v. 1, p. 21-45.

MERHY, E. E. Sobre o acolhimento na rede de serviços. Seminário sobre acolhimento, São Paulo, 12 mar. 2004b. Disponível em:

<http://bit.ly/2HAgoSN>. Acesso em: 21 fev. 2017.

MERHY, E. E.; FEUERWERKER, L. C. M. Novo

olhar sobre as tecnologias de saúde: uma necessidade contemporânea. In: MANDARINO, A. C. S.; GOMBERG, E. (Org.). Leituras de novas tecnologias e saúde. São Cristóvão: UFS, 2009. p. 29-74.

MERHY, E. E.; FEUERWERKER, L. C. M.; CECCIM, R. B. Educación permanente en salud: una estrategia para intervenir en la micropolítica del trabajo en salud. Salud Colectiva, Buenos Aires, v. 2, n. 2, p. 147-16o, 2006. Disponível em: <http://bit.ly/2EOiıPa>. Acesso em: 21 fev. 2017.

MERHY, E. E.; FEUERWERKER, L. C. M.; CERQUEIRA, M. P. Da repetição à diferença: construindo sentidos com o outro no mundo do cuidado. In: FRANCO, T. B.; RAMOS, V. C. (Org.). Semiótica, afecção e cuidado em saúde. São Paulo: Hucitec, 2010. p. 60-75.

ONOCKO CAMPOS, R. T.; CAMPOS, G. W. S. Coconstrução de autonomia: o sujeito em questão. In: CAMPOS, G. W. S. et al. (Org.). Tratado de Saúde Coletiva. 2. ed. São Paulo: Hucitec; Rio de Janeiro: Fiocruz, 2009. p. 669-688.

OPS - ORGANIZACIÓN PANAMERICANA DE LA SALUD. Prevención de la conducta suicida.
Washington, DC, 2016. Disponível em: <https:// goo.gl/8s5VAR>. Acesso em: 12 jan. 2017.

QUENTAL, I. A. Tentativas de suicídio: construindo dispositivos de prevenção. Pediatria Moderna, São Paulo, v. 45, n. 6, p. 236-240, 2009. Disponível em: <http://bit.ly/2EOtHkI $>$. Acesso em: 24 mar. 2017.

ROCHA, M. L.; AGUIAR, K. F. Pesquisa-intervenção e a produção de novas análises. Psicologia:

Ciência e Profissão, v. 23, n. 4, p. 64-73, 2003.

ROLNIK, S. Cartografia sentimental: transformações contemporâneas do desejo. Porto Alegre: Sulina: UFRGS, 2007.

SOARES, A. T. M. et al. (Org.). Prevenção do suicídio no nível local: orientações para a formação de redes municipais de prevenção e controle do suicídio e para os profissionais que a integram. Porto Alegre: Corag, 2011.

SOLOMON, A. O demônio do meio-dia: uma anatomia da depressão. 2. ed. São Paulo: Companhia das Letras, 2014.

TEIXEIRA, C. F.; SOLLA, J. P. Modelo de atenção à saúde: vigilância e saúde da família. Salvador: EDUFBA, 2006.

WERLANG, B. G.; BOTEGA, N. J. Comportamento suicida. Porto Alegre: Artmed, 2004.

WHO - WORLD HEALTH ORGANIZATION. Preventing suicide: a global imperative. Geneva, 2014. Disponível em: <https://goo.gl/ZqWlI1>. Acesso em: 30 jan. 2017.

\section{Contribuição das autoras}

Todas as autoras contribuiram para todas as etapas do estudo.

Recebido: 24/05/2017

Reapresentado: 14/01/2018

Aprovado: 06/02/2018 